\title{
Overexpression, purification, and pharmacological activity of a biosynthetically derived conopeptide
}

\author{
Ganesan Senthil Kumar, Palanisamy Ramasamy, Sujit K. Sikdar, Siddhartha P. Sarma* \\ Molecular Biophysics Unit, Indian Institute of Science, Bangalore 560012, India
}

\begin{abstract}
A high yielding fusion protein system based on the protein cytochrome $b_{5}$ has been used for the production of novel 13-residue acyclic conopeptide. This peptide, Mo1659, can be liberated from the carrier protein using CNBr cleavage and subsequent purification using RP-HPLC methods. The yield of isotopically enriched peptides is high, ranging from 3 to 4 mg of purified peptide from a $500 \mathrm{ml}$ culture, indicating that this system can be widely used for peptide production. Biosynthetic Mo1659 is active on non-inactivating $\mathrm{K}^{+}$channel much like the natural Mo1659, despite the absence of C-terminal amidation. Heteronuclear NMR studies show that the peptide exists in a conformational equilibrium involving proline-10. To our knowledge this is the first report of the production of an isotopically ${ }^{15} \mathrm{~N} /{ }^{13} \mathrm{C}$-enriched conopeptide.
\end{abstract}

Keywords: Mo1659; Conus monile; Conotoxin; Isotopic ${ }^{15} \mathrm{~N} /{ }^{13} \mathrm{C}$ labeling of peptides; cytb5 fusion; Potassium channels; Heteronuclear NMR

Studies involving peptides isolated from natural sources are hampered by the small quantities that can be purified to homogeneity. If the sequence of the peptide is known, then larger quantities may be obtained either by chemical synthesis or by recombinant DNA methods. Chemical methods are extremely useful for generating peptides, whose natural analogs contain post-translational modifications. Recombinant DNA methods have the advantage that large quantities of the peptide of interest may be prepared at a fraction

\footnotetext{
As Abreviations: RP-HPLC, reverse-phase HPLC; CNBr, cyanogen bromide; Mo1659, acyclic conopeptide isolated from Conus monile; $c y t b 5$, soluble heme binding domain of rat cytochrome $b_{5}$; NMR, nuclear magnetic resonance; IDA, iminodiacetic acid; IPTG, isopropyl- $\beta$-D-thiogalactopyranoside; TFA, trifluoroacetic acid; HSQC, heteronuclear single quantum correlation; TPPI, time-proportional phase-incrementation; DEAE, diethylaminoethyl; LC-ES-MS, liquid chromatography-electrospray mass spectrometry; MALDI-TOF, matrix-assisted laser desorption/ionization time-of-flight.

* Corresponding author. Fax: +91 8023600535.

E-mail address: sidd@mbu.iisc.ernet.in (S.P. Sarma).
}

of the cost associated with chemical synthesis. Direct expression of small peptides using common Escherichia coli strains is difficult because of the susceptibility of the expressed product to proteolysis. More commonly, the peptides of interest are expressed along with a fusion partner, as a single molecule, from which the carrier protein is cleaved by chemical or enzymatic means and finally purified. Several fusion protein systems [1-8] have been designed for the overexpression of peptides and they fall into two classes, viz., those that are expressed as insoluble proteins and those that are expressed as soluble proteins. Recently, we have shown that cytochrome $b_{5}$-based fusion protein system can be used for efficient production of proteins that are difficult to express as soluble proteins [1].

Here, we describe the overexpression and production of a small 13 residue acyclic peptide, Mo1659, using the cytochrome $b_{5}$ fusion system. Mo1659 is a novel potassium channel inhibiting conus peptide. It appears to target the non-inactivating voltage-dependent potassium channels. In an effort to characterize 
the three-dimensional structure, the channel specificity, and the mechanism of action of this toxin, we have produced large quantities of this peptide using the cytochrome $b_{5}$ fusion system. We also demonstrate that the biosynthetically produced peptide is functionally identical to the natural peptide, despite a minor C-terminal modification. Lastly, we have also prepared an isotopically ${ }^{15} \mathrm{~N} /{ }^{13} \mathrm{C}$ doubly enriched sample of the peptide for high resolution NMR studies, thereby demonstrating that this fusion protein system can prove to be cost-effective for the production of small peptides.

\section{Materials and methods}

The design and construction of the cytochrome $b_{5}$-based fusion protein has been described earlier [1]. Here, we describe the construction of the gene for the cloning, expression, isotopic enrichment, and preliminary NMR studies of Mo1659 produced using this fusion protein system. Plasmid pET 21a, E. coli strains Nova Blue and BL21(DE3) were purchased from Novagen. Oligonucleotides were custom-synthesized and purchased from Sigma-Genosys India. Enzymes for recombinant DNA technology such as Taq polymerase, T4 DNA ligase, $N d e I, E c o$ RI, and BamHI were purchased from Bangalore Genei, India, or MBI-Fermentas, Lithuania. Kits for purification of PCR fragments, plasmid extraction, and extraction of restriction fragments separated on an agarose or on a polyacrylamide gel were purchased from Qiagen, Novagen or Sigma-Aldrich. All other chemicals and biochemicals were purchased from Sigma-Aldrich, Calbiochem or Merck India. $\mathrm{Ni}^{2+}$-IDA-agarose was purchased from SigmaAldrich.

Design of the gene coding for Mo1659. A synthetic gene coding for Mo1659 was designed by backtranslation of the peptide sequence that was determined earlier [9]. The oligonucleotides representing the sense and anti-sense strands of the gene are

\section{(1) 5'-CGCGGATCCATGTTCCACGGCGGTTCCTGGTACCG TTTCCCGTGGGGTTACTGATAAGAATTCCGG-3' \\ (2) 5'-CCGGAATTCTTATCAGTAACCCCACGGGAAACGG} TACCAGGAACCGCCGTGGAACATGGATCCGCG-3'

The oligonucleotide fragments were mixed in a 1:1 stoichiometric ratio, heated to $94{ }^{\circ} \mathrm{C}$, and allowed to anneal by rapidly cooling to $4{ }^{\circ} \mathrm{C}$. The annealed product was then subjected to restriction digestion with Bam$\mathrm{HI}$ and EcoRI to introduce cohesive ends for ligation. The restriction fragment so obtained was purified from a $2 \%$ agarose gel by gel extraction. The gene coding for Mo1659 was insert ligated into the plasmid harboring the cytochrome $b_{5}$ gene that was treated with similar enzymes.

Protein expression. Plasmid containing the gene encoding for the cytochrome $b_{5}-\mathrm{Mo} 1659$ fusion protein was used to transform $E$. coli overexpression strain BL(21)DE3. Isolated colonies were picked and cultured overnight in LB broth at $37^{\circ} \mathrm{C}$. Overnight cultures served as inoculum. Large-scale protein production was accomplished by seeding a 2-L batch $(500 \mathrm{ml} \times 4$ each in $2 \mathrm{~L}$ flasks $)$ of growth media with $1 \%$ inoculum. Cultures were grown at $37{ }^{\circ} \mathrm{C}$ with shaking at $200 \mathrm{rpm}$ until the cultures reached an OD of $0.6-0.8$, at which time overexpression of protein was induced by the addition of IPTG to a final concentration of $0.5 \mathrm{mM}$. The cells were then allowed to grow for a further period of $5 \mathrm{~h}$. Cells were harvested by centrifugation $\left(5000 \mathrm{rpm}, 4^{\circ} \mathrm{C}\right)$. The supernatant was discarded and the cells were resuspended in buffer $\mathrm{A}$ (TEG-20 mM Tris-HCl, $10 \mathrm{mM}$ EDTA, and $50 \mathrm{mM}$ glucose, $\mathrm{pH} 8.0$ ) and stored overnight at $-80^{\circ} \mathrm{C}$. Frozen cells were thawed and lysed using a French press (1100 psi). Cell debris was separated from the supernatant by centrifugation $\left(12,000 \mathrm{rpm}, 4{ }^{\circ} \mathrm{C}, 30 \mathrm{~min}\right)$ and discarded. Induction of protein expression was monitored by withdrawing $1 \mathrm{ml}$ samples of culture every hour, post-induction. The cells were pelleted, lysed in Laemmli buffer, and analyzed on a 15\% SDS-PAGE gel by electrophoresis. Uniformly ${ }^{13} \mathrm{C} /{ }^{15} \mathrm{~N}$-enriched fusion protein was obtained by growth of $E$. coli in M9 minimal medium ( $500 \mathrm{ml}$ culture) containing ${ }^{13} \mathrm{C}_{6}$-glucose $(1 \mathrm{~g})$ and ${ }^{15} \mathrm{NH}_{4} \mathrm{Cl}(500 \mathrm{mg})$ as the sole source of carbon and nitrogen, respectively.

Protein purification. The supernatant from cell lysis was loaded onto a DEAE-Sephadex (Amersham) anion exchange column $(40 \mathrm{ml}$ bed volume) that had been previously equilibrated with buffer $\mathrm{B}$ ( $20 \mathrm{mM}$ Tris- $\mathrm{HCl}, \mathrm{pH} 8.0$ ). The column was then washed extensively overnight ( $\sim 20$ column volumes) with buffer B. Protein was eluted from the column by the application of a linear salt $(\mathrm{NaCl} 0-1 \mathrm{M})$ gradient. Fractions of $5 \mathrm{ml}$ volume were collected and the extent of purification was monitored by SDS-PAGE gel electrophoresis. Fractions that contained the protein were then pooled and further purified using a $\mathrm{Ni}^{2+}$-IDA chromatography step, in which the bound protein was eluted from the column by the application of a linear imidazole $(0$ $1 \mathrm{M})$ gradient. Eluted fractions from the $\mathrm{Ni}^{2+}$-IDA column were pooled and dialyzed against $10 \mathrm{mM}$ Tris $(\mathrm{pH} 8.0)$ and stored at $-20^{\circ} \mathrm{C}$ for further studies.

Mass determination. Liquid chromatography electrospray ionization (ESI) mass spectra were recorded on a Bruker Daltonics Esquire 3000 Plus Ion Trap Mass Spectrometer attached to an Agilent 1100 series HPLC system. The samples were infused into the mass spectrometer through a reverse-phase $\mathrm{C}_{18}$ column (UltraPac, $4.0 \times 250 \mathrm{~mm}, \mathrm{LKB}$, Sweden), by application of a gradient elution using a binary solvent delivery system (solvent $\mathrm{A}-0.1 \%$ formic acid in water and solvent $\mathrm{B}-0.1 \%$ formic acid in acetonitrile) at a flow rate of $0.3 \mathrm{ml} / \mathrm{min}$. The data were acquired over a $\mathrm{m} / \mathrm{z}$ range of $100-2000$ in positive ion mode and analyzed using Esquire analysis software. Matrix-assisted laser desorption/ionization time-of-flight (MALDI-TOFTOF) spectrum was acquired on a Ultraflex Bruker mass spectrometer, equipped with a nitrogen laser of wavelength $337 \mathrm{~nm}$. Samples were prepared by mixing equal amounts of peptide with the matrix solution ( $\alpha$-cyano-4-hydroxycinnamic acid) saturated with $0.1 \%$ TFA and acetonitrile $(1: 1)$

CNBr cleavage. $10 \mathrm{ml}$ of purified cytb5-monile protein $(1 \mathrm{mg} / \mathrm{ml})$ was mixed with $10 \mathrm{ml}$ of $70 \%$ formic acid containing $40 \mathrm{mg} / \mathrm{ml}$ of cyanogen bromide. The reaction was then allowed to proceed at room temperature in the dark for $16 \mathrm{~h}$. The solvent was immediately concentrated to remove formic acid using a roto-evaporator. The concentrated solution was analyzed using MALDI-TOF/TOF mass spectrometry and was purified using reverse-phase HPLC chromatography.

HPLC purification. The concentrated $\mathrm{CNBr}$ reaction product was applied onto a Ultrapac $\mathrm{C}_{18}$ column $(4 \mathrm{~mm} \times 250 \mathrm{~mm})$, already equilibrated with $95 \%$ solvent A $(0.1 \%$ TFA in water $)$ and eluted with a linear gradient of solvent B $(0.1 \%$ TFA in acetonitrile). The flow rate was maintained at $0.5 \mathrm{ml} / \mathrm{min}$ and the absorbance was monitored at $226 \mathrm{~nm}$. Fractions were collected and characterized by mass spectrometry. Fractions collected were pooled and lyophilized.

Electrophysiology. The patch-clamp technique in the whole-cell recording mode was used to study $\mathrm{K}^{+}$channel currents in mediumsized DRG (dorsal root ganglion) neurons. Dorsal root ganglion neurons for electrophysiological studies were prepared using methods described earlier [9]. The neurons were voltage-clamped with an EPC-8 patch-clamp amplifier (Heka, Germany). The external recording solution contained $(\mathrm{mM})$ : 130 choline chloride, $3 \mathrm{KCl}, 2.5 \mathrm{CaCl}_{2} \cdot 2$ $\mathrm{H}_{2} \mathrm{O}, 0.6 \mathrm{MgCl}_{2} \cdot 6 \mathrm{H}_{2} \mathrm{O}, 0.1 \mathrm{CdCl}_{2}, 10$ Hepes, $1.2 \mathrm{NaHCO}_{3}$, and 10 glucose; pH 7.4 with Tris base; osmolarity, $325 \mathrm{mOsm}$, adjusted with sucrose. Cadmium chloride was included in the external solution to block calcium currents [10]. Patch-pipette electrodes were filled with a solution containing (mM): $140 \mathrm{KCl}, 1 \mathrm{CaCl}_{2}, 2 \mathrm{MgCl}_{2} \cdot 6 \mathrm{H}_{2} \mathrm{O}, 11$ EGTA, and 10 Hepes; pH 7.2 with Tris base; osmolarity 310 mOsm. 
Data acquisition was performed using a Digidata 1320 analog/digital converter, and pClamp8 software was used for designing pulse protocols and controlling data acquisition (Axon Instruments, USA). The currents were filtered at $3 \mathrm{kHz}$ and sampled at $20 \mathrm{kHz}$. Mo1659 was dissolved in water and applied as a bolus to achieve the concentration indicated. The effects of Mo1659 on the whole-cell $\mathrm{K}^{+}$currents reported here were obtained $15 \mathrm{~min}$ after peptide application. The bath temperature was maintained at $20^{\circ} \mathrm{C}$.

NMR spectroscopy. Samples for NMR spectroscopy were prepared by dissolving the lyophilized sample of $\mathrm{Mo} 1659$ in $99 \% \mathrm{CD}_{3} \mathrm{OH}$ (Sigma-Aldrich). Sample concentration of $\sim 2 \mathrm{mM}$ was used for data acquisition. All NMR data were acquired at $283 \mathrm{~K}$ on a $700 \mathrm{MHz}$ Bruker Avance spectrometer using a triple resonance probe equipped with $z$-axis pulse field gradients. Suppression of residual water signals was achieved using the WATERGATE [11] solvent suppression pulse scheme. All multi-dimensional spectra were acquired by implementing the States-TPPI [12] method for quadrature detection in the indirect dimension(s). Proton, carbon, and nitrogen spectral widths of 10,000, 10,565, and $2838 \mathrm{~Hz}$ were employed where applicable. Proton-nitrogen HSQC [13] correlation spectrum was recorded as 1024 complex $\left(t_{2}\right) \times 64$ complex $\left(t_{1}\right)$ time domain data matrix. The ${ }^{1} \mathrm{H}-{ }^{13} \mathrm{C}$ plane of the $3 \mathrm{D}$ triple resonance $\mathrm{CBCA}(\mathrm{CO}) \mathrm{NH}[14,15]$ spectrum was acquired as a 1024 complex $\left(t_{2}\right) \times 128$ complex $\left(t_{1}\right)$ time domain data matrix. All NMR data were processed on an Intel PC workstation running Suse Linux 8.2 with NMRPipe/NMRDRAW [16] processing software.

\section{Results}

\section{Design and construction of cytb5-tev-monile}

The utility of the cytb5-based fusion protein system has been discussed elsewhere [1]. The synthetic gene was designed to contain a methionine as the residue adjacent and N-terminal to the Mo1659 peptide sequence. Fig. 1 shows the translated peptide sequence of Mo1569 including those residues introduced due to cloning exigencies. Also indicated is the cyanogen bromide cleavage site.

Expression, purification, and quantitation of cytb5-tevmonile

The cytb5-Mo1569 fusion protein expresses to very high levels. Fig. 2 shows the accumulation of the cytb5-tev-monile fusion protein as a function of time upon addition of IPTG. The yield of purified cytb5tev-monile when expressed in rich media varied from 80 to $100 \mathrm{mg} / \mathrm{L}$. Expressed fusion protein was purified initially using DEAE-anion exchange chromatography, followed by $\mathrm{Ni}^{2+}$-IDA metal affinity chromatography. About $70 \%$ of the expressed protein was present in the

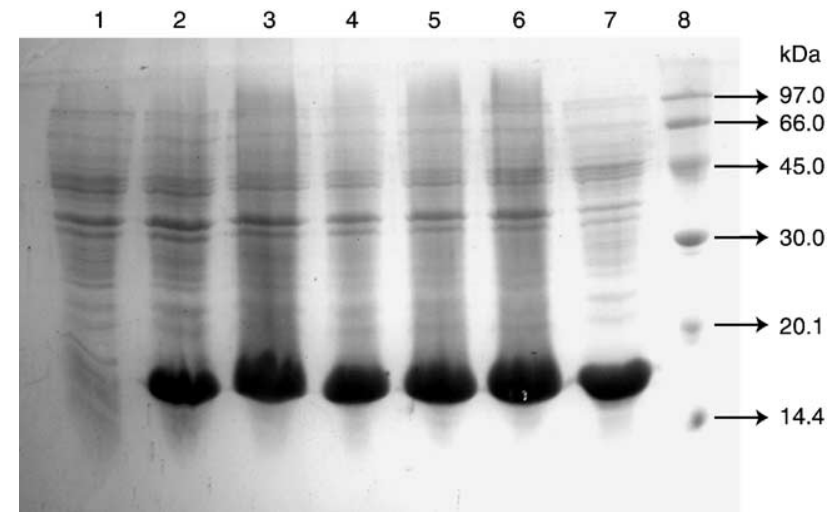

Fig. 2. SDS-PAGE gel (15\%) showing the expression levels of $c y t b 5$ tev-monile after induction with IPTG. Lanes 1-6 show the samples withdrawn at the time of induction and 1, 2, 3, 4, and $5 \mathrm{~h}$, respectively, post-induction. Lane 7 shows the supernatant after lysis of the cells. Lane 8 is the protein molecular weight marker. Six microliters of samples was loaded in lanes 1-7 and three microliters was loaded in lane 8 .

apo form. Only apo form of the expressed fusion protein binds to $\mathrm{Ni}^{2+}$-IDA column matrix [1]. The extent of purification using this method was about $100 \%$ and virtually no other protein was present as is evident from SDS-PAGE gel electrophoresis. Quantitation of the purified protein was made by measuring the absorbance values at $280 \mathrm{~nm}$ using calculated extinction coefficients. Fusion protein expressed in isotopically ${ }^{15} \mathrm{~N} /{ }^{13} \mathrm{C}$-enriched media yielded $60 \mathrm{mg} / \mathrm{L}$. Mass spectrometric studies performed on the fusion protein confirmed that the protein expressed was of full length and ruled out any possibility of truncation and proteolytic cleavage. Fig. 3 shows the LC-ESI-MS of isotopically ${ }^{15} \mathrm{~N} /{ }^{13} \mathrm{C}$ enriched cytb5-tev-monile. The observed mass of $14,715 \mathrm{Da}$ shows that the extent of isotopic enrichment to be about $97 \%$ in both carbon-13 and nitrogen- 15 .

\section{Cyanogen bromide cleavage and purification of cleaved products}

$\mathrm{CNBr}$ was used to liberate Mo1659 from cytb5-tevmonile. Fig. 4A shows the RP-HPLC profile of the $\mathrm{CNBr}$ cleaved cytb5-tev-monile. HPLC profile shows the presence of three major components in contrast to the theoretical expectation of two peaks due to the presence of a single methionine residue. The peak components were collected and characterized by mass spectrometry. Mass spectrometric studies confirmed

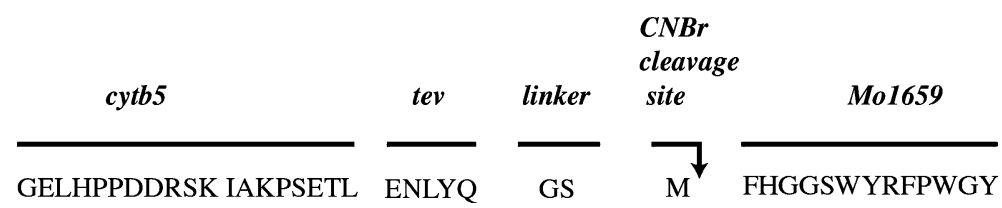

Fig. 1. Schematic illustration of cytb5-tev-monile fusion protein construct. Also shown are the $\mathrm{CNBr}$ and tev protease cleavage sites along with the C-terminal cytb5 sequence and linker region. 

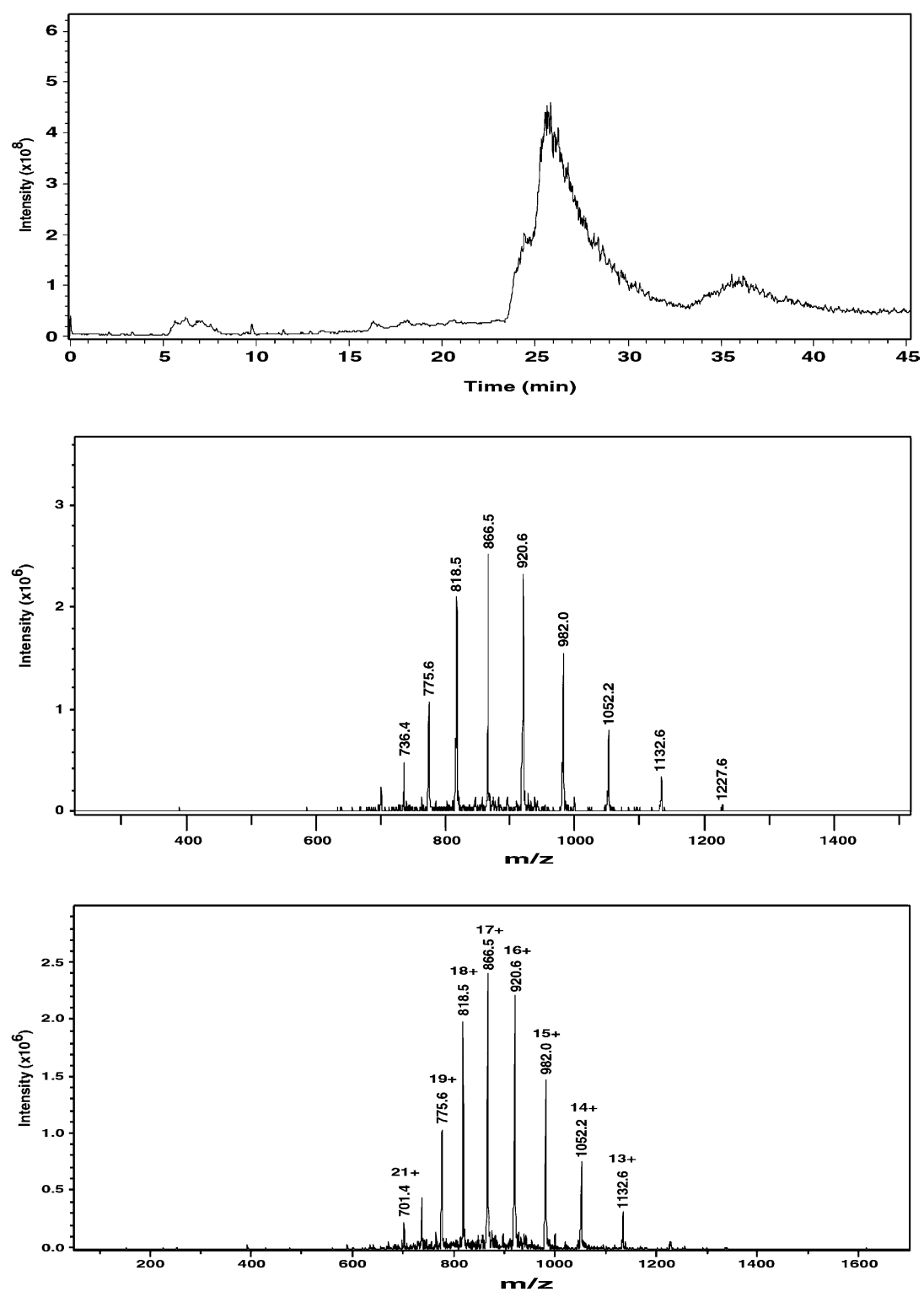

Fig. 3. LC-ESI-MS of isotopically ${ }^{15} \mathrm{~N} /{ }^{13} \mathrm{C}$-enriched cytb5-tev-monile. Also shown in the mass spectrum are the observed charge states and the corresponding $\mathrm{m} / \mathrm{z}$ values. Deconvolution of the mass spectrum results in a mass of $14,715 \mathrm{Da}$.

that the component eluting at a retention time of 22.7 min corresponded to Mo1659. Fig. 4B shows the MALDI-TOF spectrum of isotopically ${ }^{15} \mathrm{~N} /{ }^{13} \mathrm{C}$-enriched $\mathrm{CNBr}$ cleaved Mo1659. The other components corresponding to the retention times of 21.2 and 21.9 min were identified as cytb5-tev and uncut cytb5tev-monile, respectively. Fractions corresponding to Mo1659 collected from several HPLC runs were pooled, lyophilized, and stored for further NMR studies.

\section{NMR spectroscopy}

Fig. 5A shows the ${ }^{1} \mathrm{H}-{ }^{15} \mathrm{~N}$ HSQC spectrum of Mo1659. The observed chemical shift dispersion of the backbone resonances is indicative of a structured peptide in solution. In the case of Mo1659, one can expect to observe 11 correlation peaks for backbone amide proton-amide nitrogen pairs in a HSQC spectrum. However, a greater number of correlation peaks are observable in the HSQC spectrum. The possible explanations for the presence of extra resonances will be discussed (vide infra). Fig. 5B shows the plane of $3 \mathrm{D} \mathrm{CBCA}(\mathrm{CO}) \mathrm{NH}$ spectrum of Mo1659. Both $\mathrm{C}^{\alpha}$ and $\mathrm{C}^{\beta}$ correlations are observed to the amide protons in the spectrum. This is clear indication of the isotopic enrichment, since such a spectrum is not attainable at natural isotopic abundance, at least not in any realistic time.

\section{Electrophysiology}

Fig. 6 shows the effect of Mo1659 on the whole-cell outward $\mathrm{K}^{+}$currents. A reduction in the current ampli- 

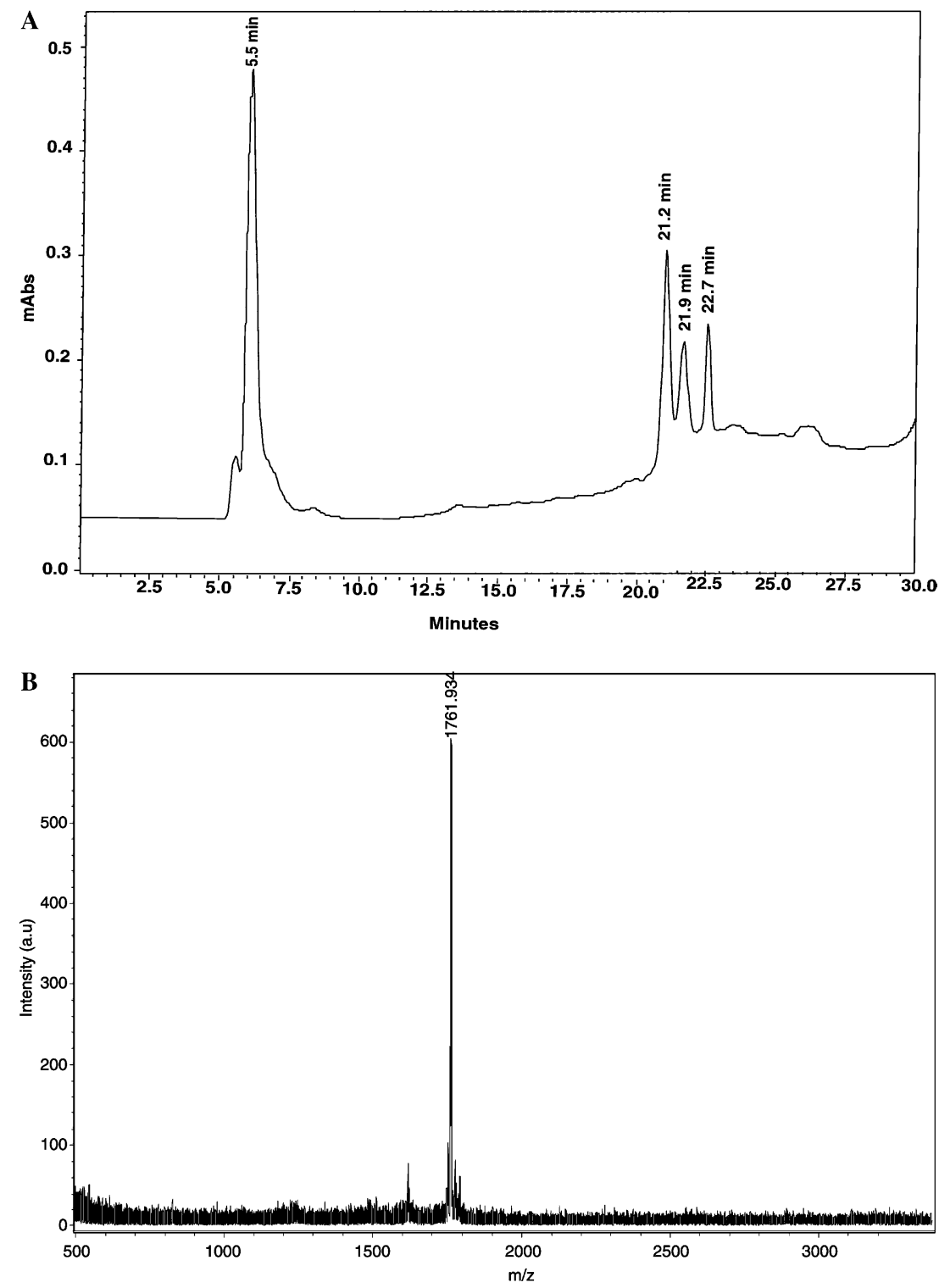

Fig. 4. (A) RP-HPLC profile of CNBr cleaved isotopically ${ }^{15} \mathrm{~N} /{ }^{13} \mathrm{C}$-enriched Mo1659. HPLC purification was performed on an Ultrapac $\mathrm{C}_{18} \mathrm{RP}$ column $(4.0 \times 250 \mathrm{~mm})$ using a linear gradient of acetonitrile containing $0.1 \%$ TFA at a flow rate of $0.5 \mathrm{ml} / \mathrm{min}$ and the absorbance was monitored at $226 \mathrm{~nm}$. (B) MALDI-TOF spectra of CNBr cleaved and purified isotopically ${ }^{15} \mathrm{~N} /{ }^{13} \mathrm{C}$-enriched Mo1659. Increase in a mass of about $100 \mathrm{Da}$ shows the uniform isotopic enrichment.

tude at all the potentials was observed in the presence of Mo1659. For the experimental data shown in Fig. 6A, the peak $\mathrm{K}^{+}$current amplitude at $30 \mathrm{mV}$ decreased from $15.44 \mathrm{nA}$ in control to $10.87 \mathrm{nA}(29.6 \%$ reduction) in $200 \mathrm{nM}$ Mo1659. A greater reduction in the current amplitude was observed when the $\mathrm{K}^{+}$currents were evoked following a prepulse to inactivate the transient $\mathrm{K}^{+}$channels that are present in these cells. In Fig. 6B, the reduction in peak $\mathrm{K}^{+}$current amplitude at $30 \mathrm{mV}$ was $54.6 \%$ (from 7.3 to $3.3 \mathrm{nA}$ ) in the presence of Mo1659. A greater reduction of the $\mathrm{K}^{+}$current elicited following a prepulse to $-40 \mathrm{mV}$ in the presence of Mo1659 suggests that the peptide preferentially attenuates the activity of the non-inactivating $\mathrm{K}^{+}$channels.
This effect is quite similar to that reported earlier for the 13 residue natural peptide of a similar sequence and molecular mass but with C-terminal amidation [9].

\section{Discussion}

Nuclear magnetic resonance has emerged as the method of choice for determining the structures of peptides and proteins in solution. It has also proved to be extremely powerful in studying the structural and conformational changes of ligands upon interaction with receptor/receptor moieties, particularly for those ligands which exhibit moderate to weak binding 

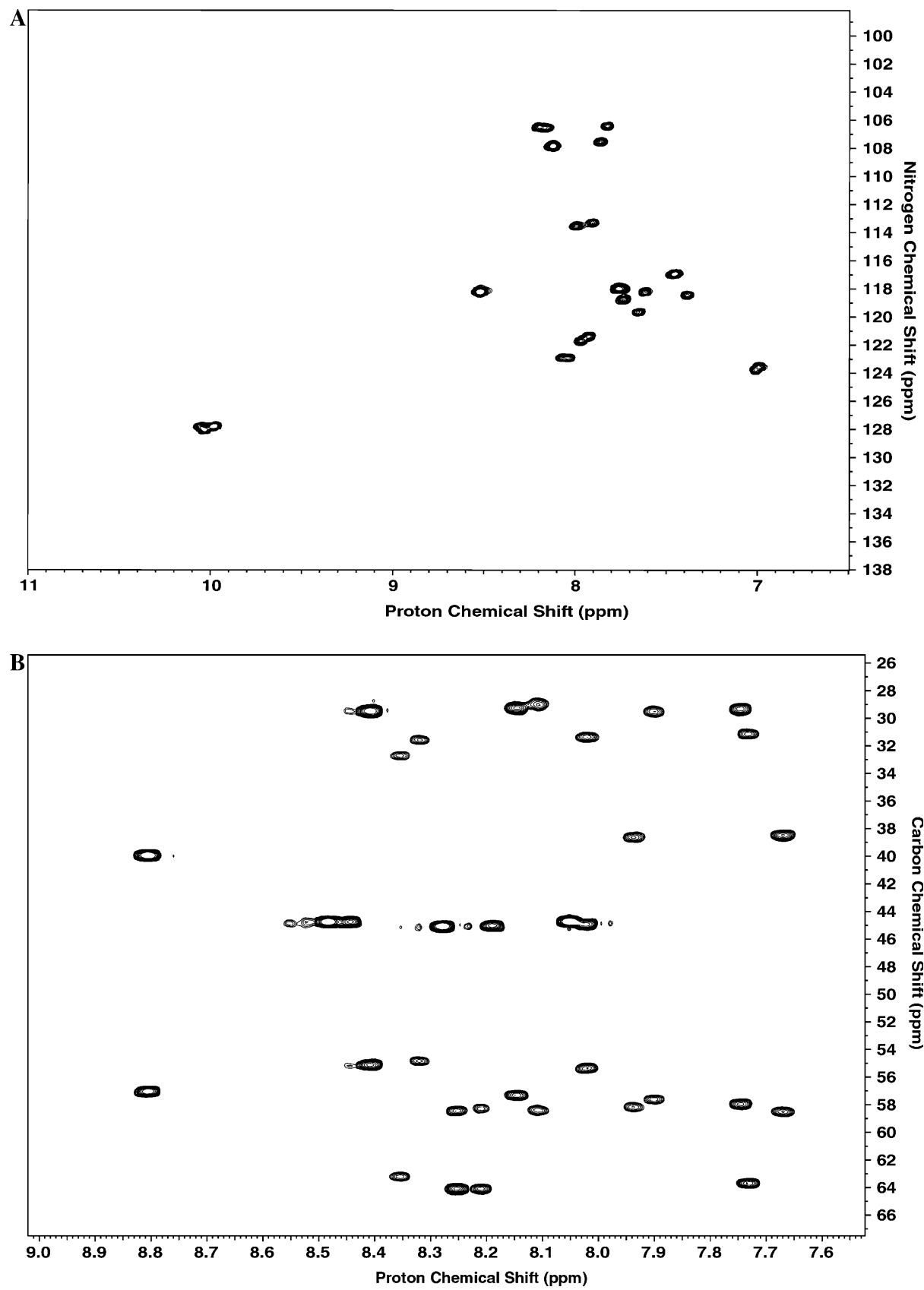

Fig. 5. (A) ${ }^{1} \mathrm{H}-{ }^{15} \mathrm{~N}$ HSQC spectrum of Mo1659. Note the increased number of correlation signals observed for a 13-residue peptide. (B) ${ }^{1} \mathrm{H}-{ }^{13} \mathrm{C}$ plane of 3D CBCA(CO)NH spectrum of Mo1659. The spectrum shows an increased number of $\mathrm{H}^{\mathrm{a}}$ and $\mathrm{H}^{\beta}$ peaks due to proline-10 cis/trans isomerization. Both the spectra were recorded at a temperature of $283 \mathrm{~K}$.

affinities. The conformational changes of peptidebased ligands are best studied using isotope edited NMR methods. The limiting factor in these studies is usually the ability to generate large amounts of such isotopically enriched peptides. Recent advances in NMR instrumentation, such as the introduction of cryogenically cooled probeheads, have enabled the acquisition of high quality NMR data at relatively lower concentrations of the analyte. The use of recombinant DNA technology for the production of isotopi- cally enriched peptides is at present the most costeffective method.

Mo1659 was isolated from Conus monile, a vermivorous cone snail found off the Indian coastal regions. Mo1659 is a potassium channel inhibiting conus peptide, which appears to target the non-inactivating voltage-dependent potassium channels [9]. The Conus peptides and conotoxins exert their pharmacological action through interaction with various ion channels and neurotransmitter receptors [17]. Study of the conforma- 


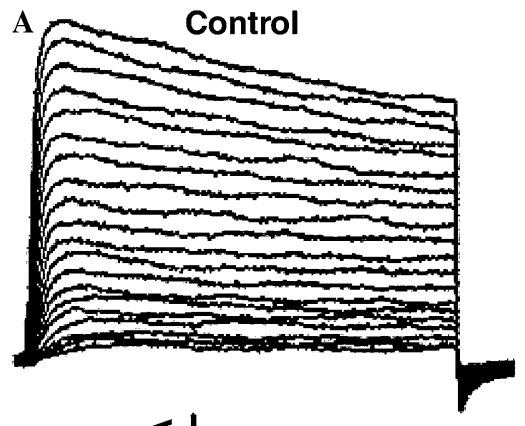

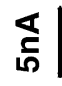

$10 \mathrm{~ms}$

+200nM Mo1659

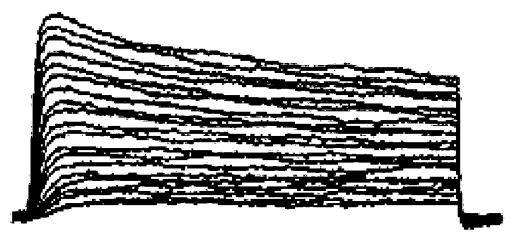

B

B Control

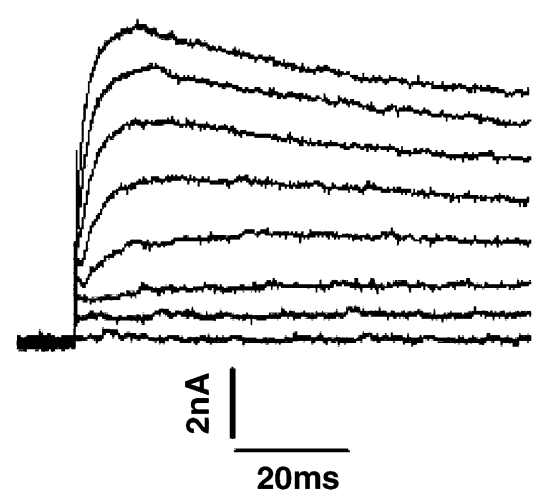

+200nM Mo1659

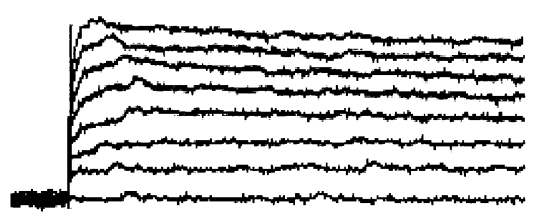

Fig. 6. Mo1659 peptide reduces whole-cell potassium currents in DRG neurons. (A) Upper set of traces show outward potassium currents in control, while the lower set of traces show potassium current recordings from the same cell in the presence of Mo1659. Currents were elicited by membrane depolarization from -50 to $100 \mathrm{mV}$ in $5 \mathrm{mV}$ steps (holding potential, $-80 \mathrm{mV}$ ). (B) Family of potassium current traces in control (upper set of traces) and in the presence of $200 \mathrm{nM}$ Mo1659 (lower set of traces) following removal of inactivation. The $\mathrm{K}^{+}$currents were elicited by voltage pulses from -40 to $+30 \mathrm{mV}$ in $10 \mathrm{mV}$ steps, following a $500 \mathrm{~ms}$ prepulse to $-40 \mathrm{mV}$ (holding potential, $-80 \mathrm{mV}$ ). The current traces in (B) are from the same cell as in (A).

tion of these peptides in complex with receptor fragments could aid in the development of pharmacological agents.

In an effort to determine the three-dimensional structure of this peptide and to study its structure in complex with $\mathrm{K}^{+}$channel receptor fragments, we have prepared an isotopically enriched sample of Mo1659 using the cytochrome $b_{5}$ fusion protein system. The method we described here enabled us to synthesize few milligrams of isotopically ${ }^{15} \mathrm{~N} /{ }^{13} \mathrm{C}$-enriched peptide Mo1659, starting from a relatively small amount of purified fusion protein. In principle, expression in a $250 \mathrm{ml}$ culture of M9 minimal media will suffice to yield sufficient quantities of the peptide to be studied by NMR methods. This is possible because of the unique properties of $c y t b 5$ as fusion host as described earlier. Moreover, the expressed fusion protein is highly stable, structured, and involves conventional purification protocols thereby making it cost-effective. Use of fusion protein systems for the expression of peptides for NMR studies has already been reported by several research groups. Most common methods involved in the separation of desired peptides from carrier protein after expression are $\mathrm{CNBr}$ cleavage and protease cleavage. Isotopic ${ }^{15} \mathrm{~N} /{ }^{13} \mathrm{C}$ labeling of peptides has already been reported using several carrier proteins with low yields. Earlier reports involving GB1 domain of protein $\mathrm{G}$ [3], RNA binding domain of hnRNCP1 [5], and ubiquitin [6] as fusion host for the production of isotopically enriched peptides resulted in low yields of peptides. The yields obtained by our fusion protein system are comparable only to the yields reported by Osborne et al. [7] using SFC120 as the fusion host. However, there are some striking differences between SFC120 and cytb5 as fusion host: (i) expressed peptides using SFC120 are directed to inclusion bodies whereas use of cytb5 resulted in peptides in soluble fraction (ii) SFC120 fusion protein system is mainly applicable for the synthesis of unfolded peptides whereas cytb5 fusion protein system resulted in the preservation of secondary structural elements as shown by CD studies (data not shown).

NMR studies of Mo1659 show that the peptide is structured in solution. The presence of additional crosspeaks in the one bond correlated amide proton-amide nitrogen spectrum is explained by the occurrence of proline cis/trans isomerization. Other possibilities such as the presence of impurities can be ruled out on the basis of the mass spectral data. Preliminary analysis of crosspeak intensities suggests that the two conformers are present in equal concentration. Proline cis/trans isomerization has been observed during the structural studies of other conotoxins [18]. The possible role of proline cis/trans isomerization as a conformational switch for regulating biological activity has been discussed [19]. The possible role of proline cis/trans conformational switching in the case of conotoxins has not been exam- 
ined. The availability of an isotopically enriched sample of Mo1659 will enable unambiguous assignment of both conformers using heteronuclear NMR methods. Furthermore, the spectral dispersion afforded by these methods will also enable tracking of conformational changes upon receptor binding as also the motional properties of both conformers.

An important distinguishing feature of this biosynthetic peptide from the natural peptide is the absence of the C-terminal amidation, which results in an increase in mass $1 \mathrm{Da}$. C-terminal amidation is one of the most commonly found post-translational modifications in conotoxins. In spite of this change, the biosynthetically derived Mo1659 is active on $\mathrm{K}^{+}$channels present in rat DRG neurons.

In summary, we have described in this paper the use of cytb5-based fusion protein system for the large-scale production of isotopically ${ }^{15} \mathrm{~N} /{ }^{13} \mathrm{C}$-enriched peptides with high yields without abolishing the pharmacological activity of the biologically active peptides. We have also concluded that the C-terminal amidation plays no vital role in the biological activity as far as Mo1659 is concerned.

\section{Acknowledgments}

The NMR and Mass Spectrometric Facilities at the Indian Institute of Science are funded from grants by DBT and DST. The authors thank Professor Raghavan Varadarajan for access to his HPLC. G.S.K. is supported by a University Grants Commission Senior research fellowship.

\section{References}

[1] A. Mitra, K.S. Chakrabarti, M.S.S. Hameed, K.V. Srinivas, G.S. Kumar, S.P. Sarma, High level expression of peptides and proteins using Cytochrome b5 as a fusion host, Protein Expr. Purif. 41 (2005) 84-97.

[2] A. Kuliopulos, C.T. Walsh, Production, purification and cleavage of tandem repeats of recombinant peptides, J. Am. Chem. Soc. 116 (1994) 4599-4607.

[3] A.P. Campbell, D.L. Bautista, B. Tripet, W.Y. Wong, R.T. Irvin, R.S. Hodges, B.D. Sykes, Solution secondary structure of bacterially expressed peptide from the receptor binding domain of Pseudomonas aeruginosa Pili strain PAK: a heteronuclear multidimensional NMR study, Biochemistry 36 (1997) 1280112971.

[4] J. Zhan, X. Chen, C. Wang, J. Qiu, F. Ma, K. Wang, S. Zheng, A fusion protein of conotoxin MVIIA and Thioredoxin expressed in
Escherichia coli has significant analgesic activity, Biochem. Biophys. Res. Commun. 311 (2003) 495-500.

[5] M. Sharon, M. Gorlach, R. Levy, Y. Hayek, J. Anglister, Expression, purification and isotopic labeling of a gp120 V3 peptide and production of a Fab from HIV-1 neutralising antibody for NMR studies, Protein Expr. Purif. 24 (2002) 374 383.

[6] T. Kohno, H. Kusunoki, K. Sato, K. Wakamatsu, A new general method for the biosynthesis of stable isotope-enriched peptides using a decahistidine-tagged Ubiquitin fusion system: an application to the production of mastoparan-X uniformly enriched with ${ }^{15} \mathrm{~N}$ and ${ }^{15} \mathrm{~N} /{ }^{13} \mathrm{C}$, J. Biomol. NMR 12 (1998) $109-121$.

[7] M.J. Osborne, Z. Su, V. Sridaran, F. Ni, Efficient expression of isotopically labeled peptides for high resolution NMR studies: application to the $\mathrm{Cdc} 42 / \mathrm{Rac}$ binding domains of virulent kinases in Candida albicans, J. Biomol. NMR 26 (2003) 317-326.

[8] W.D. Fairlie, A.D. Uboldi, D.P. Desouza, G.J. Hemmings, N.A. Nicola, M. Bacca, A fusion protein system for the recombinant production of short disulfide containing peptides, Protein Expr. Purif. 26 (2002) 171-178

[9] S. Sudarslal, G. Singaravadivelan, P. Ramasamy, K. Ananda, S.P. Sarma, S.K. Sikdar, K.S. Krishnan, P. Balaram, A novel 13 residue acyclic peptide from the marine snail, Conus monile, targets potassium channels, Biochem. Biophys. Res. Commun. 317 (2004) 682-688.

[10] B. Everill, M.A. Rizzo, J.D. Kocsis, Morphologically identified cutaneous afferent DRG neurons express three different potassium currents in varying proportions, J. Neurophysiol. (1998) 1814 1824.

[11] M. Piotto, V. Saudek, V. Sklenar, Gradient tailored excitation for single quantum NMR spectroscopy of aqueous solutions, J. Biomol. NMR 2 (1992) 661-665.

[12] D. Marion, M. Ikura, R. Tschudin, A. Bax, Rapid recording of 2D NMR spectra without phase cycling. Application to the study of hydrogen exchange in proteins, J. Magn. Reson. 85 (1989) 393-399.

[13] S. Mori, C. Abeygunawardana, M. Johnson, P.C.M. Van zijl, Improved sensitivity of HSQC spectra of exchanging protons at short interscan delays using a new Fast HSQC (FHSQC) detection scheme that avoids water saturation, J. Magn. Reson. Ser. B 108 (1995) 94-98

[14] S. Grzesiek, A. Bax, Aminoacid type determination in the sequential assignment procedure of uniformly ${ }^{13} \mathrm{C} /{ }^{15} \mathrm{~N}$-enriched proteins, J. Biomol. NMR 3 (1993) 185-204.

[15] S. Grzesiek, A. Bax, Correlating backbone amide and side chain resonances in larger proteins by multiple relayed triple resonance NMR, J. Am. Chem. Soc. 114 (1992) 6291-6293.

[16] F. Delaglio, S. Grzesiek, G.W. Vuister, G. Zhu, J. Pfeifer, A. Bax, NMRPipe: a multidimensional spectral processing system based on UNIX pipes, J. Biomol. NMR 6 (1995) 277-293.

[17] H. Terlau, B.M. Olivera, Conus venoms: a rich source of novel ion channel-targeted peptides, Physiol. Rev. 84 (2004) 41-86.

[18] A.H. Andreotti, Native state proline isomerization: an intrinsic molecular switch, Biochemistry 42 (2003) 9515-9524.

[19] L. Volpon, H. Lamthanh, J. Barbier, N. Gilles, J. Molgo, A. Menez, J. Lancelin, NMR solution structures of $\delta$-conotoxin EVIA from Conus ermineus that selectively acts on vertebrate neuronal $\mathrm{Na}^{+}$channels, J. Biol. Chem. 279 (2004) 21356 21366. 